\title{
Icariin enhances the chemosensitivity of cisplatin-resistant ovarian cancer cells by suppressing autophagy via activation of the AKT/mTOR/ATG5 pathway
}

\author{
SHAOYAN JIANG, HONG CHANG, SHAOJIE DENG and DANYI FAN \\ Department of Pharmacy, Shenzhen Maternity and Child Healthcare Hospital, Shenzhen, Guangdong 518028, P.R. China
}

Received January 30, 2018; Accepted December 12, 2018

DOI: 10.3892/ijo.2019.4785

\begin{abstract}
Icariin is a flavonoid derived from Epimedium sagittatum, and has a wide range of biological and pharmacological effects; however, little is known regarding its effect on drug-resistant ovarian cancer and the signal transduction pathways underlying the regulation of apoptosis and autophagy. The present study aimed to investigate the re-sensitization effects of icariin exerted on an ovarian cancer cell line. Autophagy was analyzed in a SKVCR cell line that had been treated with icariin. We investigated the sensitivity of SKVCR cells to cisplatin, as well as the effects of an autophagy agonist (rapamycin) on autophagy, apoptosis, and the protein kinase B (AKT) signaling pathway. Finally, the mechanism underlying the effects of autophagy-related (ATG) protein ATG5 overexpression on autophagy, apoptosis and AKT signaling in SKVCR cells were determined. The results revealed that treatment with icariin inhibited cell viability and autophagy, but promoted G0/G1 phase cell cycle arrest and apoptosis as determined by Cell Counting Kit-8, immunofluorescence and flow cytometry assays, respectively. Icariin reduced the resistance of SKVCR cells to cisplatin in vitro by inducing G1/S cell cycle transition, apoptosis and inhibiting autophagy. Furthermore, enhanced autophagy induced by rapamycin treatment or overexpression of ATG5 partially reversed the effect of icariin on cisplatin resistance and autophagy in SKVCR cells. At the molecular level, rapamycin treatment or overexpression of ATG5 reversed the effects of icariin on the expression of autophagy-associated proteins, including
\end{abstract}

Correspondence to: Dr Shaoyan Jiang, Department of Pharmacy, Shenzhen Maternity and Child Healthcare Hospital, 2004 Hongli Road, Futian, Shenzhen, Guangdong 518028, P.R. China

E-mail: syjiangdoc@163.com

Abbreviations: CCK-8, Cell Counting Kit-8; ESCC, esophageal squamous cell carcinoma; IC50, half-maximal inhibitory concentration; mTOR, mammalian target of rapamycin; OC, ovarian cancer; PI3K, phosphoinositide 3-kinase; PI, propidium iodide

Key words: icariin, ovarian cancer, chemosensitivity, autophagy, protein kinase $\mathrm{B} / \mathrm{mTOR}$ microtubule-associated protein 1 light chain $3 \beta$, Beclin-1, ATG5 and p62, and the AKT/mammalian target of rapamycin (mTOR) pathway. Collectively, our results suggested that icariin enhances the chemosensitivity of SKVCR cells by suppressing autophagy via activation of the AKT/mTOR signaling pathway.

\section{Introduction}

Ovarian cancer (OC) is an aggressive gynecological cancer with a high propensity for postmenopausal women (1). In the United States, 22,240 women were diagnosed with OC, and $63 \%$ of those patients were expected to succumb to mortality from this disease (2). Surgery and platinum-based chemotherapy remain the standard treatment for patients with advanced stage III ovarian cancer; however, the clinical outcomes are unsatisfactory, which is mainly due to the late diagnosis and resistance of the cancer cells to chemotherapeutic agents $(1,3,4)$. Therefore, there is an urgent need for novel therapies that can enhance the sensitivity of ovarian cancer cells to chemotherapy.

Autophagy is a cellular catabolic process in which autophagosomes are formed, and proteins, organelles and the cytosol undergo lysosomal digestion and recycling (5). Autophagy serves a key role in various physiopathological processes, including oncogenesis, cellular development, apoptosis and survival $(6,7)$. Accumulating evidence indicates that autophagy, which occurs in response to stressful conditions and specific environmental factors, including nutrient deprivation, pathogen infection and chemotherapeutic agents, can promote cell survival $(8,9)$. Despite being a protective response to stimuli, the self-degradation undertaken via autophagy can also damage critical cellular components, leading to autophagic cell death (type 2 cell death; apoptosis is considered as type 1 cell death) (10). The various outcomes of autophagy are associated with specific circumstances and certain molecular pathways (11).

Thephosphoinositide3-kinase/proteinkinaseB/mammalian target of rapamycin (PI3K/AKT/mTOR) signaling pathway is a major regulator of autophagy in eukaryote cells, and is involved in cell growth, viability, migration and apoptosis, particularly during cancer development, metastasis and chemotherapy-resistance $(12,13)$. PI3K activation stimulates its downstream target AKT to activate mTOR, leading to suppression of autophagy (14). Conversely, inactivation of AKT/mTOR signaling promotes dissociation of the Unc-51 
like autophagy activating kinase 1-autophagy-related (ATG) protein 13-FAK family-interacting protein of $200 \mathrm{kDa}$ complex from mTOR1 and induce the autophagy process (15). Recently, several PI3K/AKT/mTOR-targeted compounds have been reported in problems affecting the application of chemotherapy agents, including drug resistance, undesirable pharmacokinetics and toxicity (16). The class-III-PI3K inhibitor, 3-methyladenine suppresses autophagy in colon cancer and esophageal squamous cell carcinoma (ESCC) cells, and thereby increases their sensitivity to the chemotherapeutic agents fluorouracil and cisplatin, respectively $(17,18)$. Rottlerin promotes the apoptosis of human pancreatic cancer stem cells by inducing autophagy via the suppression of the PI3K/AKT/mTOR signaling pathway (19).

Icariin is aflavonoid extract obtained from several Epimedium species; it prevents neuroinflammation and decreases cellular damage produced by oxidative stress (20). Icariin demonstrates its antiapoptotic and anti-autophagic effects in bone marrow-derived endothelial progenitor cells by promoting cell migration and capillary tube formation (21). Additionally, icariin decreases oxygen-glucose deprivation and reperfusion-induced autophagy in rat pheochromocytoma (PC12) cells by promoting cross talk between autophagy and apoptosis-associated pathways mediated by B-cell lymphoma-2 (Bcl-2) (22). It also inhibits tumor oncogenesis and the development of human ESCC by inducing stress signaling in the endoplasmic reticulum (23). In SKVCR cells, a potential anticancer function of icariin has been associated with dysregulation of miR-21, phosphatase and tensin homolog, reversion-inducing-cysteine-rich protein with kazal motifs and Bcl-2 (24). Cisplatin, a platinum-containing chemotherapeutic drug, is one of the most effective agents against a wide variety of solid tumors, including ovarian, lung, breast and colon tumors (25). In our previous study, we concluded that icariin can serve an anti-cancerous role by inhibiting autophagy (26); however, the specific mechanism remains unknown.

In the present study, we report the novel finding that icariin attenuates autophagy in SKVCR cells, which leads to an exacerbation of cisplatin-induced cell growth inhibition by activation of the PI3K/AKT/mTOR pathway. Improving understanding into the biological functions of autophagy and pharmacological regulators of autophagy may provide a basis for treating cisplatin resistance in OC.

\section{Materials and methods}

Drug and reagents. Icariin and cisplatin were purchased from Sigma-Aldrich (Merck KGaA, Darmstadt, Germany). A Cell Counting Kit-8 (CCK-8) was purchased from Dojindo Molecular Technologies, Inc. (Kumamoto, Japan). Antibodies against Bax (SC-7480), caspase-3 (SC-7148), p62 (rabbit polyclonal), and Beclin-1 (rabbit polyclonal) were obtained from Santa Cruz Biotechnology, Inc. (Dallas, TX, USA). Antibody against microtubule-associated protein 1 light chain $3 \beta$ (LC3B; L7543) was purchased from Sigma-Aldrich (Merck KGaA). Antibodies against cleaved caspase-3 (cat. no. 9661), Akt (cat. no. 4691), phosphorylated (p)-Akt (Ser473), mTOR (cat. no. 2972), p-mTOR (Ser2448), ATG5 (8540S), and GAPDH (cat. no. 2118) were obtained from Cell Signaling Technology, Inc. (Danvers, MA, USA). Annexin V-fluorescein isothiocyanate (FITC) and propidium iodide (PI) were purchased from Sigma-Aldrich (Merck KGaA).

Cell culture and drug treatment. The human multidrug-resistant phenotype OC cell line SKVCR (SKVCR0.015) was obtained from the Cell Bank of the Chinese Academy of Sciences (Shanghai, China). The OC cells were cultured in $\alpha$-minimum essential medium supplemented with $10 \%$ fetal bovine serum (FBS, Gibco; Thermo Fisher Scientific, Inc., Waltham, MA, USA) in a humidified atmosphere containing $5 \% \mathrm{CO}_{2}$ at $37^{\circ} \mathrm{C}$. The experiments involved five groups of cells that were treated as follows: i) A control group with no drug treatment (blank); ii) an icariin treatment group (10, 20 and $30 \mu \mathrm{g} / \mathrm{ml})$; iii) a cisplatin treatment group $(10 \mu \mathrm{M})$; iv) a group treated with cisplatin followed by icariin $1 \mathrm{~h}$ later [cisplatin $(5 \mu \mathrm{g} / \mathrm{ml})+$ icariin $(20 \mu \mathrm{g} / \mathrm{ml})$ group]; and $\mathrm{v})$ a group treated with cisplatin + icariin followed by treatment with rapamycin [cisplatin + icariin + rapamycin $(0.1 \mu \mathrm{M})$ group]. All cells were maintained for $48 \mathrm{~h}$ at $37^{\circ} \mathrm{C}$ in a humidified atmosphere containing $5 \% \mathrm{CO}_{2}$.

Plasmids and transfection. The cDNA sequence of ATG5 was synthesized based on its mRNA sequences by Sangon Biotech Co. Ltd. (Shanghai, China) with restriction sites $(K p n \mathrm{I}$ and $\mathrm{BamHI}$ ) and inserted into a pcDNA3.1 plasmid to construct a recombinant pcDNA3.1-ATG5 vector. Cells were grown in 6-well plates to $60 \%$ confluence, and then transfected with pcDNA3.1-ATG5 or empty pcDNA plasmid as a negative control using Lipofectamine ${ }^{\circledR} 2000$ according to the manufacturer's protocols (Invitrogen; Thermo Fisher Scientific, Inc.). The mass concentration of all transfectants was $100 \mathrm{ng} / \mathrm{ml}$.

Cell viability assay. Cells were seeded into 96-well plates at a density of $1 \times 10^{4}$ cells $/ \mathrm{ml}$ and incubated for $24 \mathrm{~h}$ at $37^{\circ} \mathrm{C}$ in a humidified atmosphere containing $5 \% \mathrm{CO}_{2}$; after which, they were treated with icariin or cisplatin. Then, $10 \mu 1$ of CCK-8 solution was added to each well, and the plates were incubated for $2 \mathrm{~h}$ in an incubator at $37^{\circ} \mathrm{C}$. The optical density value of each well was measured at $450 \mathrm{~nm}$ with a microplate reader (BioTek Instruments, Inc., Winooski, VT, USA).

Flow cytometric analysis of the cell cycle and apoptosis. Cells that received the different drug treatments were harvested and fixed overnight at $4^{\circ} \mathrm{C}$ with $70 \%$ ethanol; after which, they were resuspended in $500 \mu \mathrm{l}$ PBS. For the cell cycle assay, $10 \mu \mathrm{l}$ RNase $(10 \mathrm{mg} / \mathrm{ml})$ was added to an aliquot of cultured cells, and the cells were incubated for $30 \mathrm{~min}$ at $37^{\circ} \mathrm{C}$. The cells were then stained with $10 \mu \mathrm{l}$ PI $(1 \mathrm{mg} / \mathrm{ml})$, and their DNA content was analyzed with a flow cytometer (BD Biosciences, San Jose, CA, USA). For cell the apoptosis assay, cells were harvested, washed twice with cold PBS, and then incubated with $100 \mu \mathrm{l}$ binding buffer containing $5 \mu \mathrm{l}$ Annexin V-FITC and $1 \mu \mathrm{l}$ PI working solution $(100 \mu \mathrm{g} / \mathrm{ml})$ for $30 \mathrm{~min}$ at room temperature in the dark. The cells were then analyzed with a flow cytometer (BD Biosciences). Apoptosis was analyzed using FlowJo 7.6 software (FlowJo LLC, Ashland OR, USA), and cell cycle was processed by ModFit software version 3.2 (Verify Software House, Inc., Topsham, ME, USA). The apoptotic rate was calculated as follows: Apoptotic rate $=$ early 
apoptotic rate (right lower percentage) + later apoptotic rate (right upper percentage).

Transmission electron microscopy (TEM) analysis TEM was used to detect autophagosomes as previously described $(27,28)$. Briefly, cells were fixed in $2.5 \%$ glutaraldehyde and $0.1 \mathrm{M}$ cacodylate buffer for $2 \mathrm{~h}$ at $4^{\circ} \mathrm{C}$. Following digestion with trypsin (1:250) for $1 \mathrm{~min}$ at $37^{\circ} \mathrm{C}$, the cells were rinsed twice with precooled PBS, and posted-fixed in $1 \%$ osmium tetroxide at room temperature for $1 \mathrm{~h}$. The fixed cells were then washed with PBS buffer solution, and dehydrated with gradient alcohol (50, 70, 90 and 100\%), and embedded in epoxy resin. The ultrastructure of cells undergoing autophagy were observed and imaged under a transmission electron microscope (JEM-1200; JEOL, Ltd., Tokyo, Japan) performed at $80 \mathrm{kV}$.

Immunofluorescence assay. Cell autophagy was assessed by immunofluorescence staining. Briefly, cells were fixed in $4 \%$ paraformaldehyde for $5 \mathrm{~min}$ at $4^{\circ} \mathrm{C}$ and washed three times with PBS (5 min per wash). After washing, the cells were blocked with 5\% non-fat milk in $0.1 \%$ Triton X-100 at room temperature for $1 \mathrm{~h}$, and then incubated with anti-LC3B primary antibodies (1:1,000; Sigma-Aldrich; Merck KGaA) for $1 \mathrm{~h}$ at $4^{\circ} \mathrm{C}$. Then, the cells were incubated with Alexa Fluor-labeled secondary antibodies (1:500; Sigma-Aldrich; Merck KGaA) for $1 \mathrm{~h}$ and washed with PBS. DAPI was used as a counterstain to identify the nucleus at $4^{\circ} \mathrm{C}$ for $10 \mathrm{~min}$. The stained cells were visualized using immunofluorescence microscopy (BX60; Olympus Corporation, Tokyo, Japan) under five non-overlapping fields (magnification, x200).

Western blot analysis. Total cellular proteins were extracted using radioimmunoprecipitation assay buffer (Beyotime Institute of Biotechnology, Haimen China) and quantified by a Bicinchoninic Acid method. Aliquots containing $~ 30 \mu \mathrm{g}$ total proteins were subjected to SDS-PAGE, and the separated protein bands were transferred onto a polyvinylidene difluoride membrane (EMD Millipore, Billerica, MA, USA). Subsequently, the membrane was blocked with $5 \%$ nonfat milk for $1 \mathrm{~h}$ at $4^{\circ} \mathrm{C}$ and then incubated with several primary antibodies, including anti-Bax, anti-caspase-3, anti-LC3B, anti-p62, anti-Beclin-1, anti-Akt, anti-p-Akt, anti-mTOR, anti-p-mTOR, anti-ATG5 and anti-GAPDH at $4^{\circ} \mathrm{C}$ overnight. Following washing with PBS, the membranes were incubated with a horseradish peroxidase-conjugated secondary antibody (1:5,000; Beijing Zhongshan Jinqiao Biotechnology Co., Ltd., Beijing, China) for $2 \mathrm{~h}$ at room temperature. The chemiluminescent staining signals were detected using an enhanced chemiluminescence detection system (Bio-Rad Laboratories, Inc., Hercules, CA, USA). GAPDH was used as an internal control. This experiment was repeated three times independently.

Statistical analysis. All data are expressed as the mean \pm standard deviation. All statistical parameters were calculated using GraphPad Prism 6.01 software (GraphPad Software Inc., La Jolla, CA, USA). One-way analysis of variance followed by a Tukey's post-hoc test was used for data analysis. $\mathrm{P}<0.05$ was considered to indicate a statistically significant difference. In experiments were repeated three times independently.

\section{Results}

Icariin treatment suppresses cell viability and cell cycle progression, and activates apoptosis and autophagy in $O C$ cells. To investigate whether icariin could exert antitumor activity in SKVCR cells, the CCK-8 assay was used to evaluate cell viability following treatment with different concentrations of icariin. As presented in Fig. 1A, icariin treatment significantly decreased the percentage of viable SKVCR cells in a dose-dependent manner, and the half-maximal inhibitory concentration $\left(\mathrm{IC}_{50}\right)$ value of icariin was $\sim 60 \mu \mathrm{g} / \mathrm{ml}$. Based on this $\mathrm{IC}_{50}$ value, the effects of icariin on cell cycle progression and apoptosis by were analyzed flow cytometry. Furthermore, icariin treatment significantly increased the percentage of apoptotic cells, including cells in early apoptosis or late apoptosis $(\mathrm{P}<0.001$; Fig. 1B). As presented in Fig. 1C, the percentage of SKVCR cells in G0/G1 phase significantly increased following icariin treatment, which was accompanied with a reduction in the number of $S$ phase cells in the icariin group when compared with the control group $(\mathrm{P}<0.001)$. TEM analysis was performed to observe whether icariin affected the ultrastructure of SKVCR cells. As presented in Fig. 1D, autophagic vacuoles were detected in the blank control group; however, fewer were observed following icariin treatment. We further confirmed the occurrence of autophagy via an immunofluorescence assay using staining with anti-LC3B. When compared with the blank group, the ratio LC3B I/II was significantly lower in the icariin group, suggesting that icariin treatment could significantly reduce the occurrence of autophagy (Fig. 1E and F).

Icariin treatment sensitizes OC cells to cisplatin. In addition, how icariin may mediate the viability of SKVCR cells treated with cisplatin was investigated. A CCK-8 assay revealed that combined treatment with icariin and cisplatin significantly suppressed the viability of SKVCR cells when compared with cisplatin treatment alone $(\mathrm{P}<0.001$; Fig. $2 \mathrm{~A})$. This indicated that icariin enhanced the inhibitory effects of cisplatin on SKVCR cell viability. Additionally, icariin treatment significantly induced cell apoptosis $(\mathrm{P}<0.01$; Fig. $2 \mathrm{~B}$ and $\mathrm{C})$ and cycle arrest at the G0/G1 phase $(\mathrm{P}<0.001$; Fig. 2D and $\mathrm{E})$ in cisplatin-treated SKVCR cells. Western blot analysis suggested that the expression levels of Bax and caspase-3 proteins were notably upregulated (Fig. 2F). Furthermore, LC3B II was notably downregulated by icariin compared with the blank group, and cells treated with cisplatin and icariin presented markedly higher LC3B II expression compared with cells treated with icariin (Fig. 2F).

Enhanced autophagy reduces the sensitivity of ovarian cancer cells to icariin. The aforementioned results demonstrated that icariin treatment could notably sensitize ovarian cancer cells to cisplatin and inhibit autophagy. As autophagy is negatively correlated with the efficacy of chemotherapy $(29,30)$, it was hypothesized that enhanced autophagy may affect the sensitivity of $\mathrm{OC}$ cells to icariin and cisplatin. As presented in Fig. 3A and B, icariin markedly suppressed cisplatin-induced autophagy, while rapamycin, an autophagy activator, notably alleviated the suppressive effects of icariin on SKVCR cells, as determined by TEM and immunofluorescence analysis, 
A

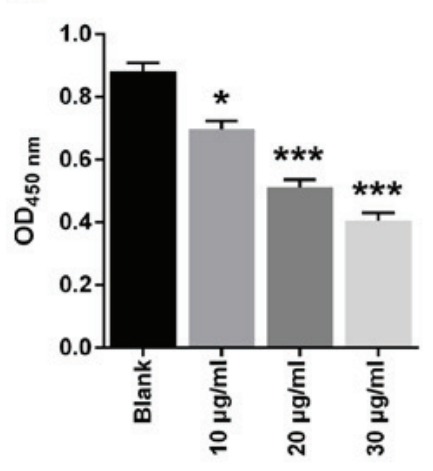

B
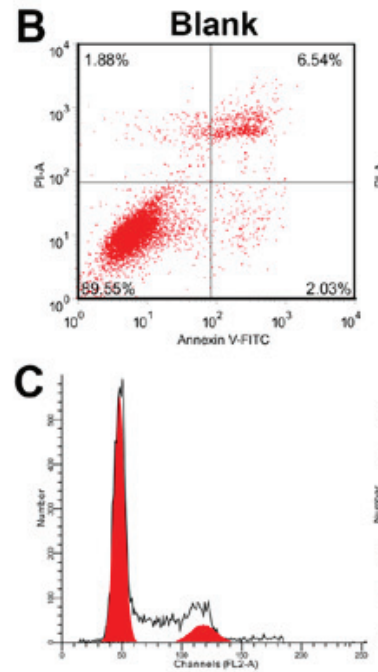
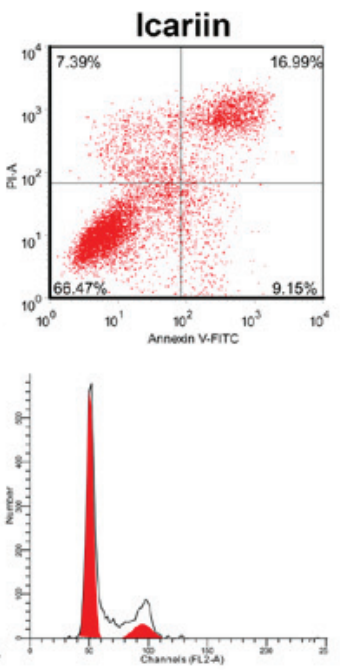
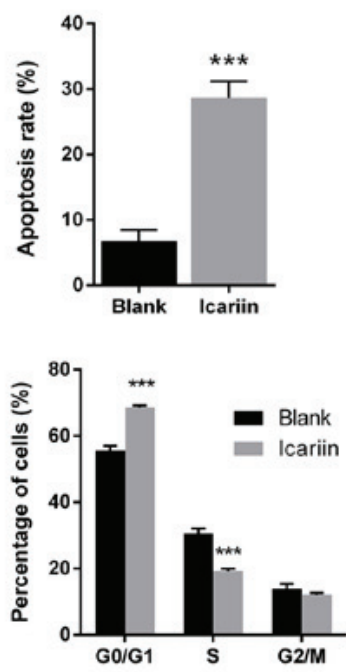

D

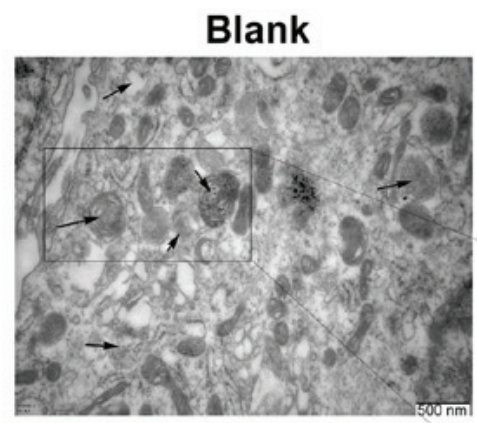

$\mathbf{E}$

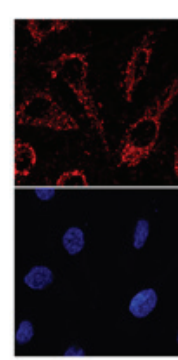

Blank

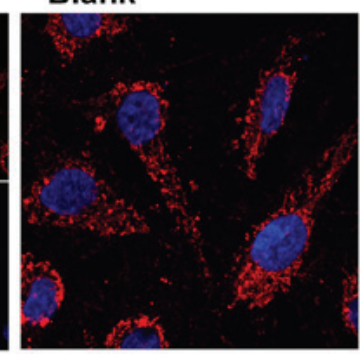

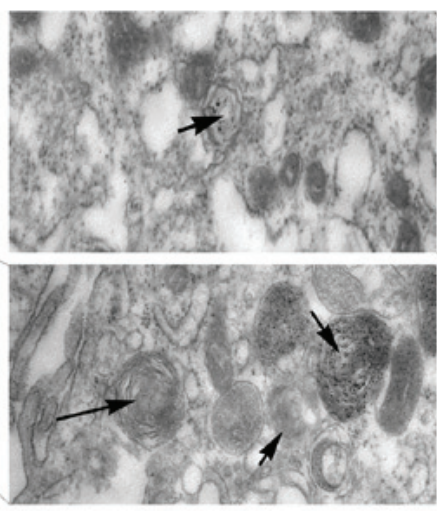

Icariin

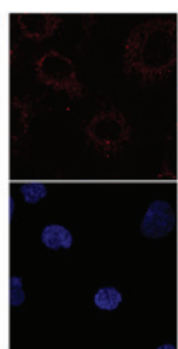

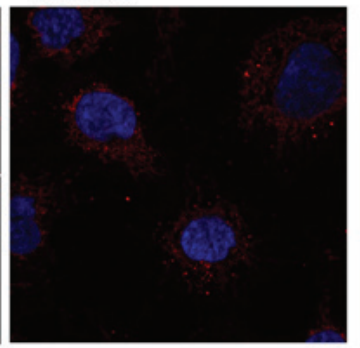

Icariin
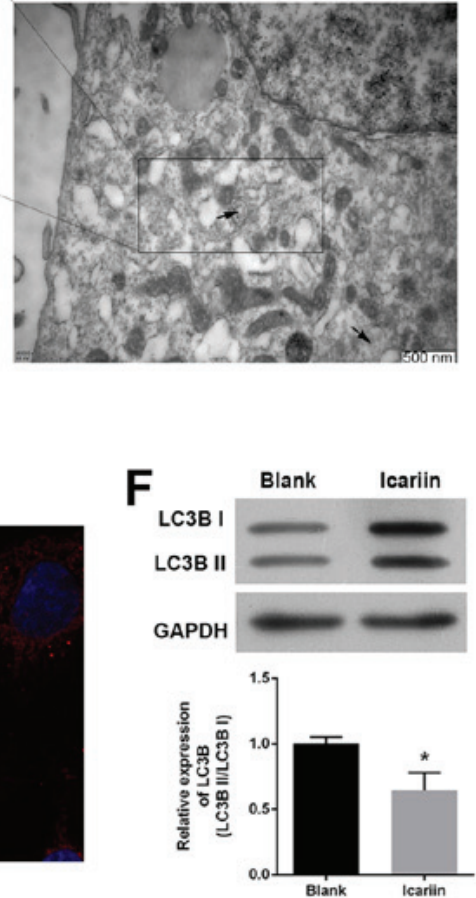

Figure 1. Effects of icariin on cell viability, cell cycle distribution, apoptosis and autophagy in SKVCR cells. (A) Cell Counting Kit-8 assay was used to determine the proliferative ability of SKVCR cells treated with icariin (10, 20, and $30 \mu \mathrm{g} / \mathrm{ml}$, respectively). (B) Flow cytometry combined with Annexin V-FITC and PI staining was used to analyze cell apoptosis in SKVCR cells treated with icariin ( $20 \mu \mathrm{g} / \mathrm{ml})$. (C) Flow cytometry combined with PI staining was used to analyze the cell cycle distribution of SKVCR cells treated with icariin $(20 \mu \mathrm{g} / \mathrm{ml})$. (D) A transmission electron microscope image of cell autophagosomes $(20 \mu \mathrm{g} / \mathrm{ml})$. Scale bar, $500 \mathrm{~nm}$. (E and F) An immunofluorescence assay was used to examine LC3B expression in SKVCR cells treated with icariin (20 $\mu \mathrm{g} / \mathrm{ml})$. Magnification, $\mathrm{x} 200$. $^{*} \mathrm{P}<0.05,{ }^{* * *} \mathrm{P}<0.001$ vs. Blank group. FITC, fluorescein isothiocyanate; LC $3 \mathrm{~B}$, microtubule-associated protein 1 light chain $3 \beta$; PI, propidium iodide; OD, optical density.

respectively. In addition, flow cytometry was used to analyze cell cycle distribution and apoptosis rates. As presented in Fig. 3C-F, the enhanced autophagy induced by rapamycin significantly reversed the inhibitory effects of icariin on cell cycle progression and apoptosis $(\mathrm{P}<0.05)$. The molecular mechanisms underlying the effects of rapamycin on autophagy were investigated via western blotting. As presented in Fig. 3G, the levels of LC3B, Beclin-1 and ATG5 expression were downregulated, while that of p62 was upregulated in the cisplatin + icariin group, when compared with the groups treated with cisplatin or rapamycin alone, suggesting that icariin treatment could suppress autophagy induced by cisplatin or rapamycin. Furthermore, icariin activated the AKT/mTOR pathway, as demonstrated by upregulation of p-AKT and p-mTOR; however, rapamycin treatment reversed the effects of icariin on the expression of autophagy-associated proteins. Collectively, these data suggested that the increase in chemosensitivity induced by icariin could be reversed by the enhanced autophagy triggered by rapamycin (Fig. 3G).

Upregulation of ATG5 reduces the sensitivity of $O C$ cells to icariin. ATG5 is one of several well-established 

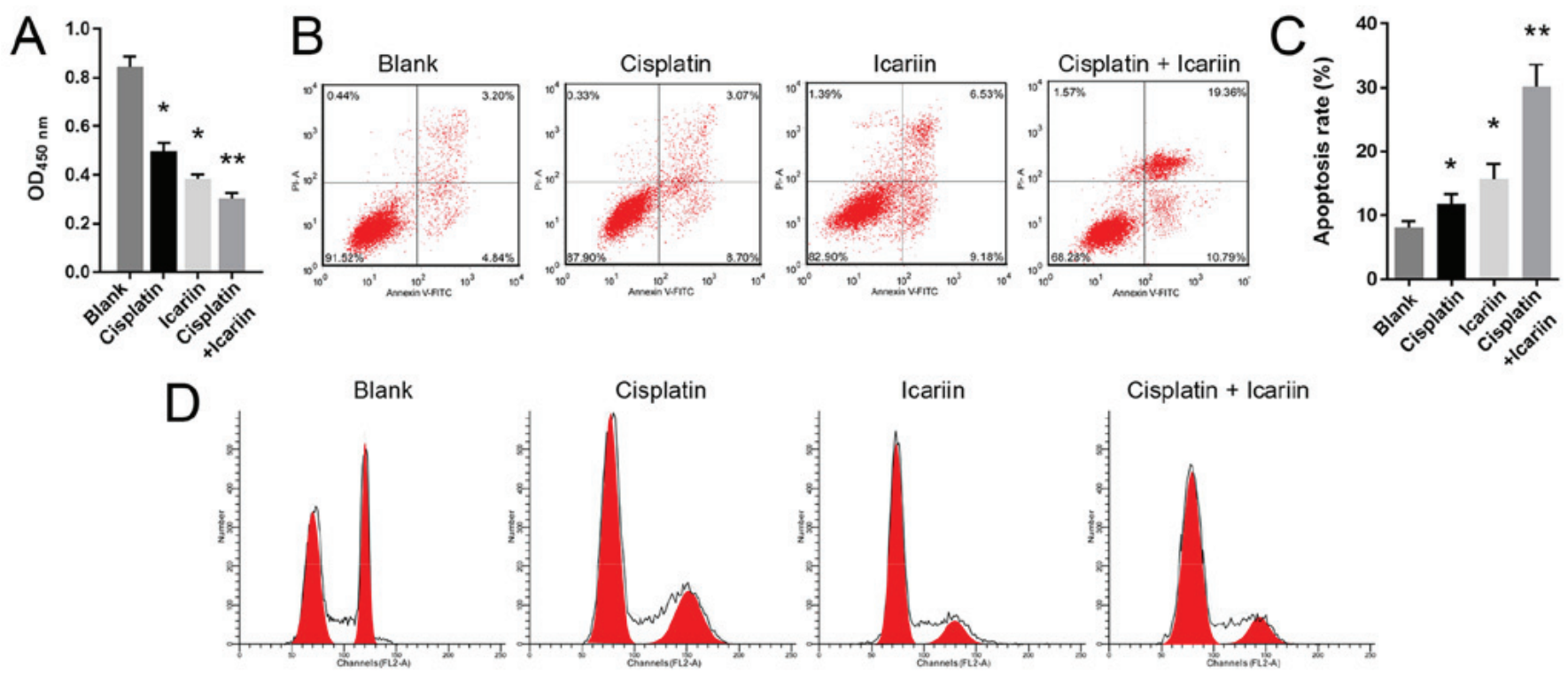

Cisplatin + Icariin
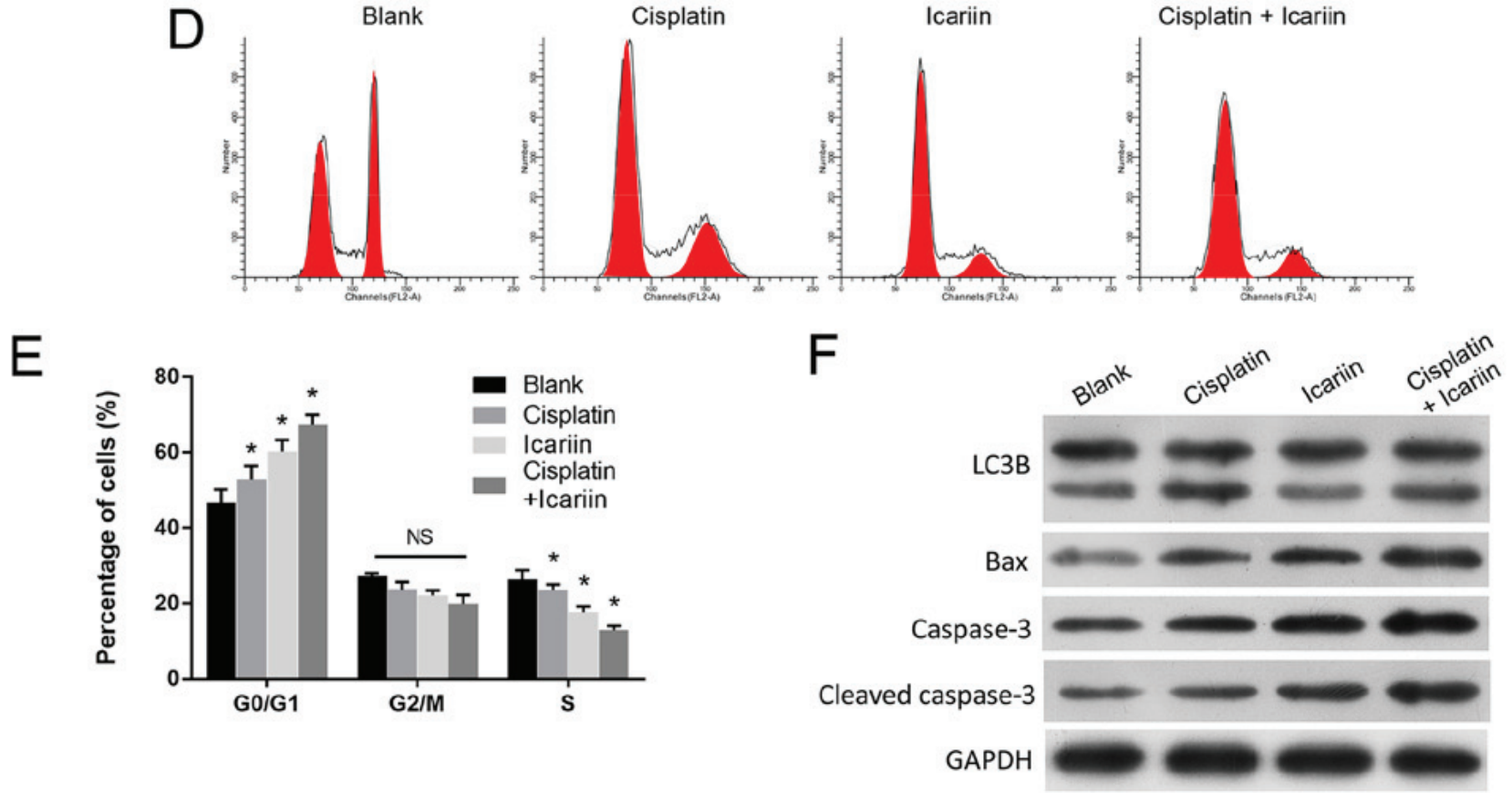

Figure 2. Icariin treatment enhances the chemosensitivity of SKVCR cells to cisplatin. (A) Cell Counting Kit-8 assay was used to assess the viability of SKVCR cells in the cisplatin group and cisplatin + icariin group. Flow cytometry was used to analyze (B and C) apoptosis and (D and E) the cell cycle distributions in SKVCR cells. (F) Expression levels of Bax and caspase-3 proteins in SKVCR cells were analyzed by western blotting. GAPDH was used an internal control. Icariin, $20 \mu \mathrm{g} / \mathrm{ml}$; cisplatin, $5 \mu \mathrm{g} / \mathrm{ml}$. " $\mathrm{P}<0.05$ and ${ }^{* *} \mathrm{P}<0.001$ vs. Blank group. Bax, B-cell lymphoma 2-associated-X; FITC, fluorescein isothiocyanate; LC3B, microtubule-associated protein 1 light chain $3 \beta$; NS, not significant; OD, optical density.

autophagy-associated proteins, and is critical for the biogenesis of autophagosomes (31). It was reported that knockdown of ATG5 promoted cisplatin-induced apoptotic death of human lung cancer cells (32). To further confirm the association between autophagy and chemotherapy, overexpression of ATG5 was conducted in SKVCR cells following treatment with icariin + cisplatin. As expected, the results of TEM (Fig. 4A) and immunofluorescence revealed that cisplatin or overexpression of ATG5 enhanced autophagy compared with the blank group; however, overexpression of ATG5 reversed the decreased autophagy in the icariin + cisplatin group (Fig. 4A and B). Consistent with this finding, the promoting effects of icariin on cell apoptosis $(\mathrm{P}<0.05$; Fig. $4 \mathrm{C}$ and $\mathrm{D})$ and the cell cycle $(\mathrm{P}<0.01$; Fig. 4E and F) in cisplatin-resistant SKVCR cells was significantly alleviated by ATG5 overexpression. Western blot analysis was also conducted to examine the expression of autophagy- and apoptosis-associated proteins. As presented in Fig. 4G, compared with blank group, the levels of LC3B, Beclin-1 and ATG5 were markedly increased in cisplatin-treated cells or ATG5-overexpressing cells, which was accompanied with p62 downregulation. While, cells treated with cisplatin and icariin exhibited weaker levels of autophagy-associated protein compared with ATG5-overexpressing cells. The activity of the AKT/mTOR signaling cascade in icariin-treated cells was notably enhanced as demonstrated by increased expression levels of activated p-AKT and p-mTOR, but was impaired by ATG5 overexpression. Importantly, ATG5, a promoter of autophagy, was downregulated by icariin treatment. Collectively, these results further demonstrated that icariin had enhanced the sensitivity of SKVCR cells to cisplatin, partially by inhibiting autophagy.

\section{Discussion}

In the present study, the underlying mechanism as to how icariin modulates the viability, apoptosis and autophagy of SKVCR cells was investigated, and provide a possible mechanism for how icariin increases the sensitivity of SKVCR cells to cisplatin was proposed. In our previous study, it was suggested that icariin can inhibit malignant phenotypes in ovarian cancer cell lines by inhibiting autophagy (26). To the best of our knowledge, the present study is the first to 

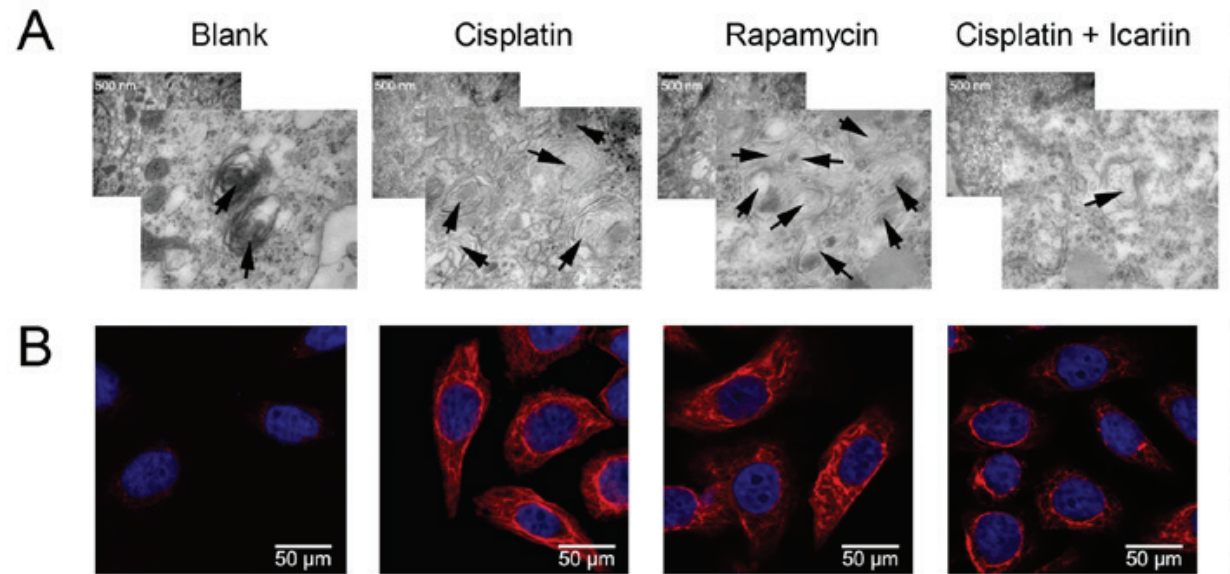

Cisplatin + Icariin
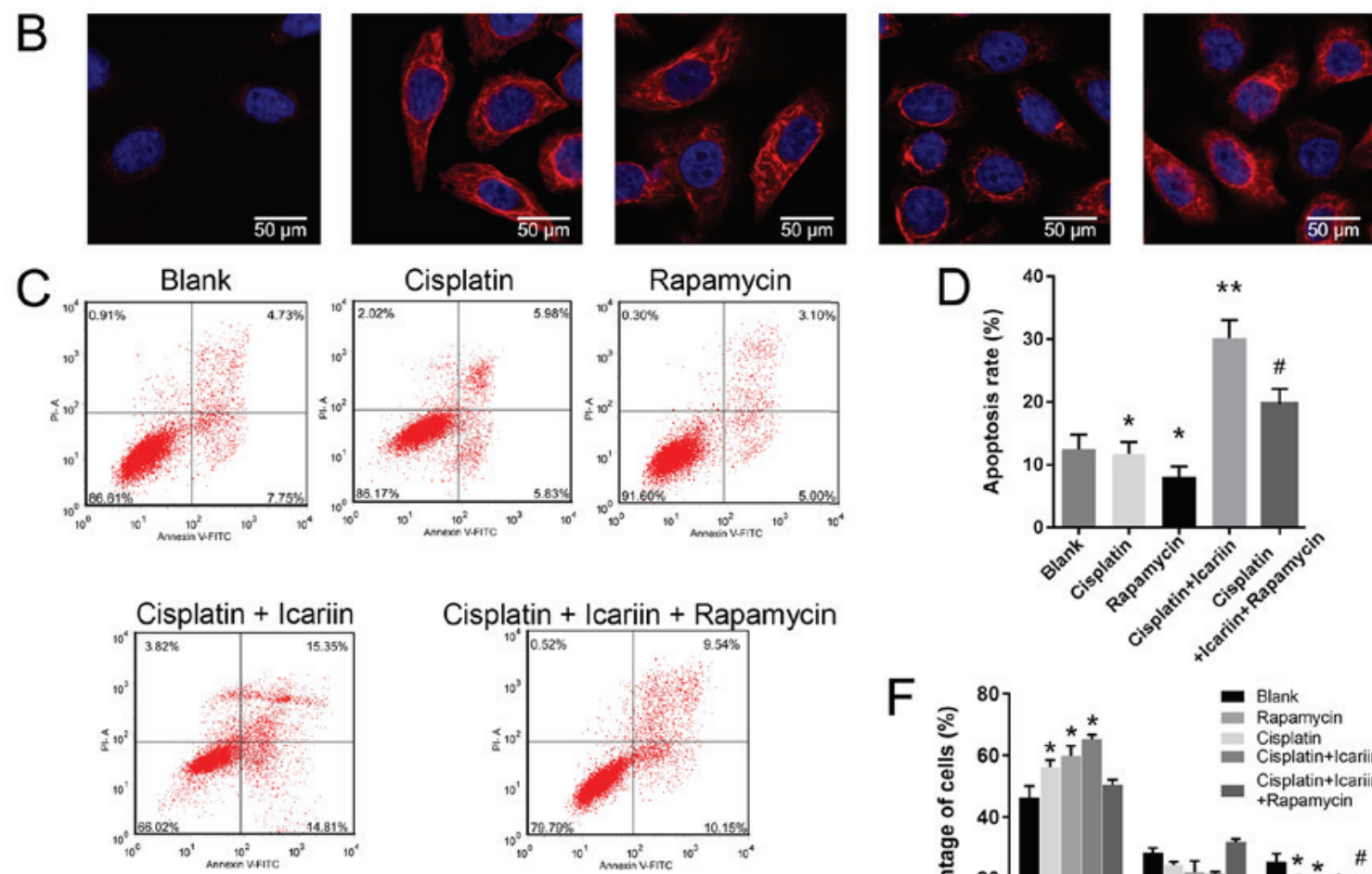

$E$

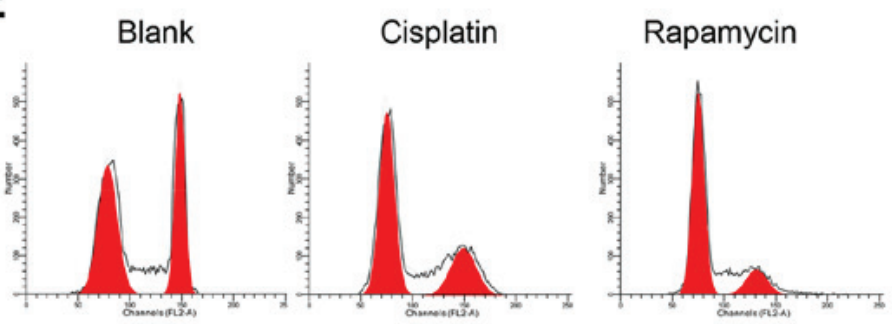

$\mathrm{F}$
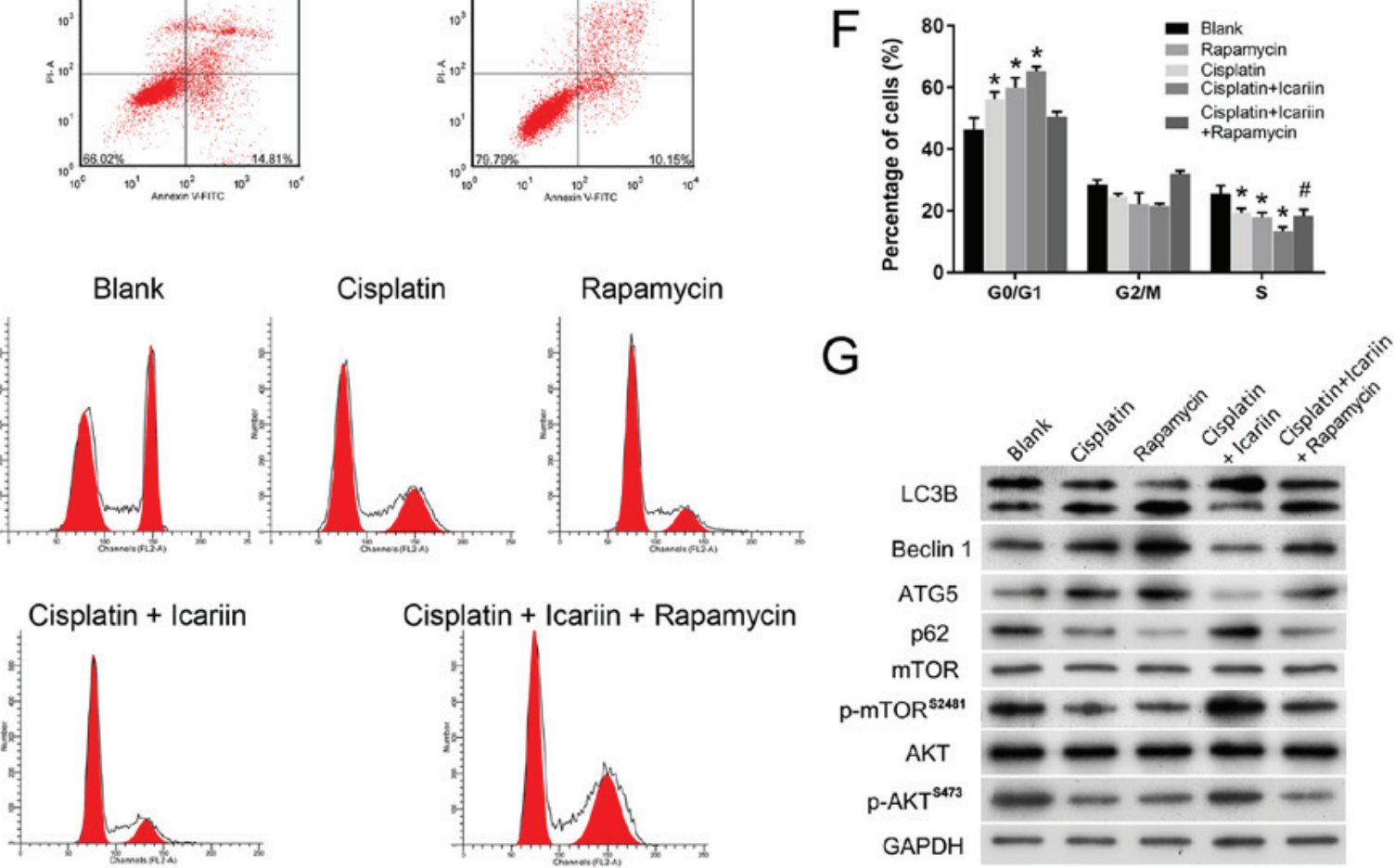

Figure 3. Enhanced autophagy reduces the sensitivity of ovarian cancer cells to icariin. (A) Transmission electron microscope images of autophagosomes in SKVCR cells. Scale bar, $500 \mathrm{~nm}$. (B) LC3B expression in SKVCR cells was examined using an immunofluorescence assay. Scale bar, $50 \mu \mathrm{m}$. Flow cytometry was used to analyze (C and D) the cell apoptosis and (E and F) the cell cycle distribution in SKVCR cells. (G) Expression levels of LC3B, Beclin-1, ATG5, p62, AKT, p-AKT, mTOR and p-mTOR proteins in SKVCR cells were determined by western blot analysis. GAPDH was used an internal control. Icariin, $20 \mu \mathrm{g} / \mathrm{ml}$, cisplatin, $5 \mu \mathrm{g} / \mathrm{ml}$. " $\mathrm{P}<0.05$ vs. Blank group; ${ }^{* *} \mathrm{P}<0.01$ vs. cisplatin group; ${ }^{*} \mathrm{P}<0.05$ vs. cisplatin + icariin group; AKT, protein kinase $\mathrm{B}$; ATG5, autophagy-related 5; LC3B, microtubule-associated protein 1 light chain 3 $\beta ;$ p, phosphorylated; mTOR, mammalian target of rapamycin.

demonstrate that icariin can enhance the sensitivity of SKVCR cells to cisplatin via inhibiting autophagy by inducing cell apoptosis and inhibiting the cell cycle.

Cisplatin is a platinum-based drug that forms inter- and intra-strand DNA crosslinks, and is used as a first-line chemotherapeutic agent in treating epithelial ovarian carcinoma (22). Compared with cisplatin treatment, the results indicated that treatment with cisplatin + icariin induced apoptosis in SKVCR cells and inhibited the viability of those cells. Furthermore, we observed a corresponding decrease 

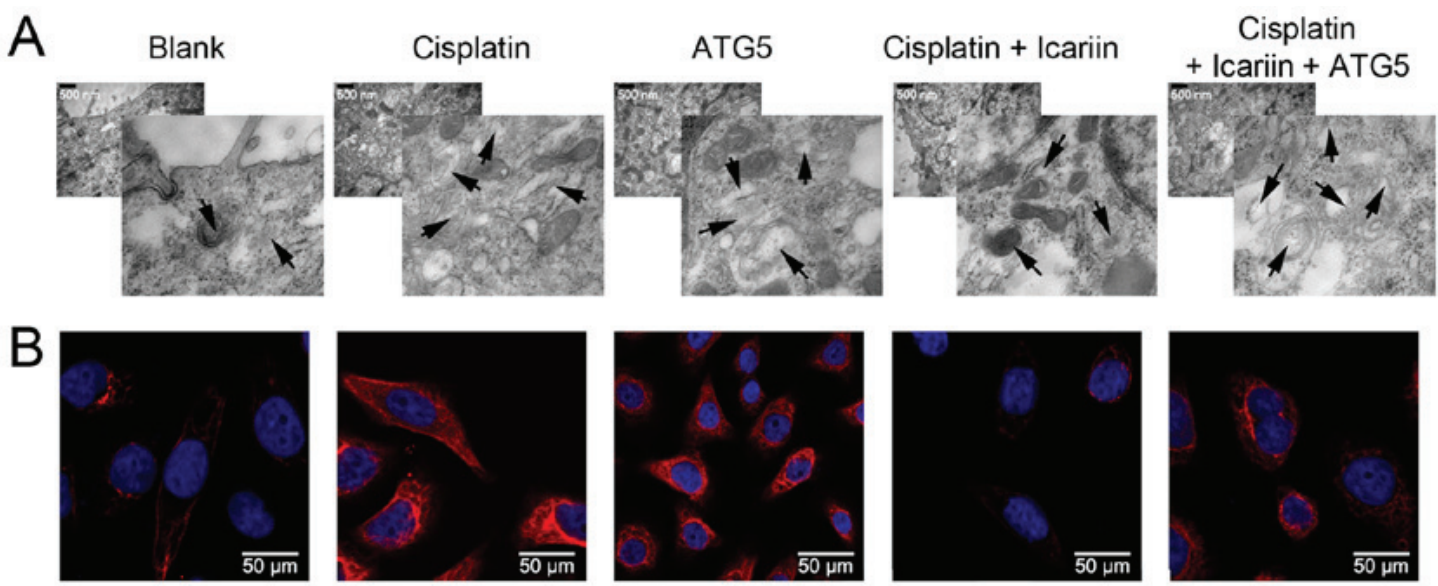

C
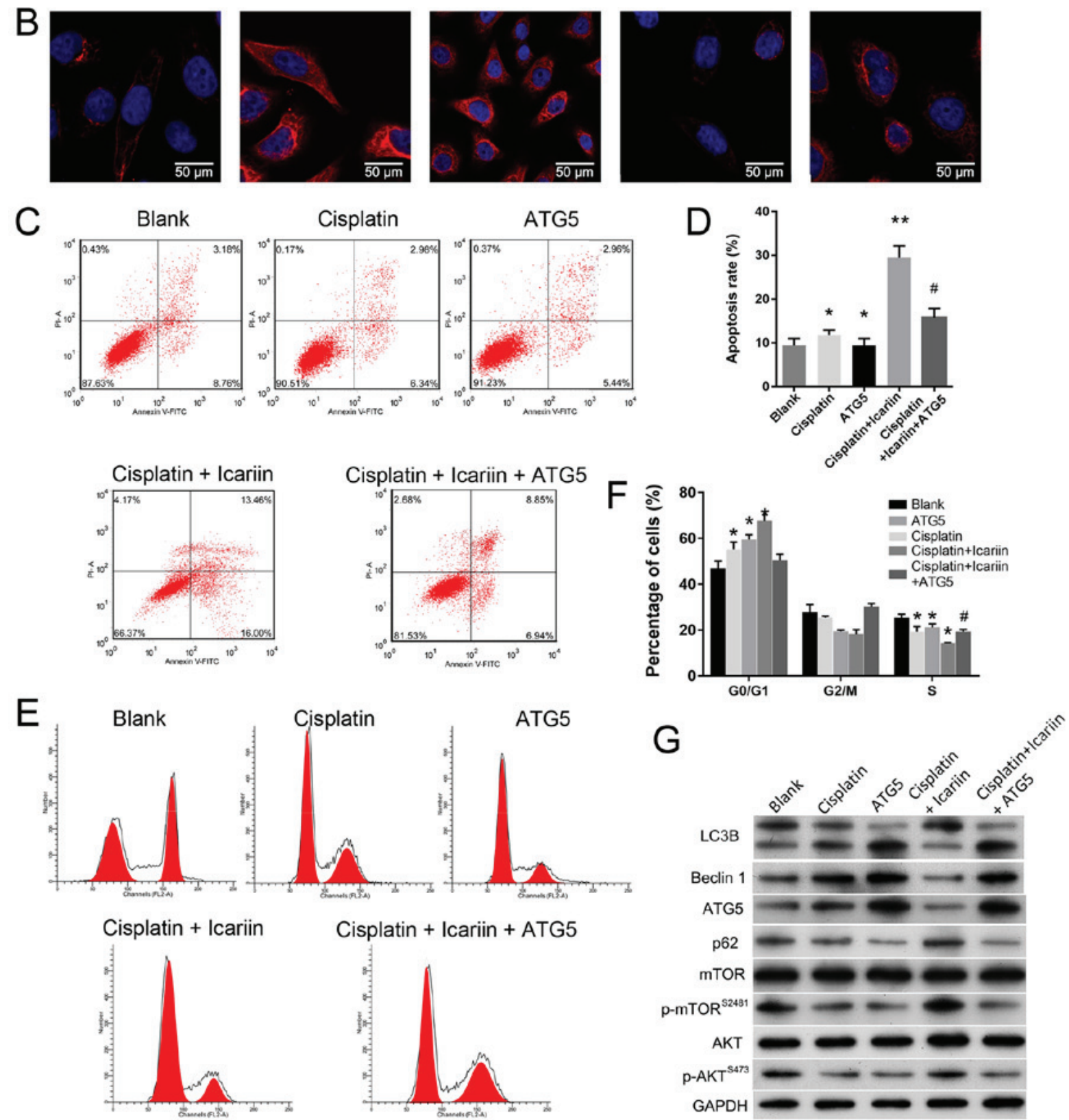

Figure 4. Upregulation of ATG5 reduces the sensitivity of ovarian cancer cells to icariin. (A) Transmission electron microscopy analysis of autophagosomes in SKVCR cells. Scale bar, $500 \mathrm{~nm}$. (B) LC3B expression in SKVCR cells was examined using via immunofluorescence analysis. Scale bar, $50 \mu \mathrm{m}$. Flow cytometry was used to analyze (C and D) the cell apoptosis and (E and F) the cell cycle distribution in SKVCR cells. (G) The levels of LC3B, Beclin-1, ATG5, p62, AKT, p-AKT, mTOR, p-mTOR and caspase-3 proteins in SKVCR cells were determined by western blot analysis. Icariin, $20 \mu \mathrm{g} / \mathrm{ml}$, cisplatin, $5 \mu \mathrm{g} / \mathrm{ml}$. ${ }^{*} \mathrm{P}<0.05$ vs. Blank group; ${ }^{* *} \mathrm{P}<0.01$ vs. cisplatin group; ${ }^{~} \mathrm{P}<0.05$ vs. cisplatin + icariin group. AKT, protein kinase $\mathrm{B}$; ATG5, autophagy-related 5; LC3B, microtubule-associated protein 1 light chain $3 \beta ;$ p, phosphorylated; mTOR, mammalian target of rapamycin.

in autophagy, which suggests a role for icariin in regulating autophagy in cisplatin-treated SKVCR cells.

Autophagy is a lysosomal pathway that delivers cellular components, including proteins, organelles and cytosol to lysosomes, where they are degraded to maintain cellular homeostasis (33). It has been reported that that autophagy is modulated by extracellular and intracellular stress, as well as signaling pathways (34). A variety of proteins are involved in the progression of autophagy. ATG5 is essential for autophagosome formation and autophagy promotion (35). 
Beclin-1 is a central component of the PI3K-III complex, which recruits several autophagy proteins during the formation of autophagosomes (36). An efficient autophagy recycling process relies on numerous proteins, including LC3B, which is an autophagy indicator that is cleaved into LC3B I and LC3B II during autophagy (37). LC3B serves an essential role in the biogenesis of autophagosomes and recruitment of autophagosome cargo (37). A previous study demonstrated that p62 can bind to ubiquitin and LC3B, and a lack of autophagy is usually accompanied with the downregulation of p62 (38). In the present study, when compared with OC cells treated with cisplatin alone, treatment with cisplatin + icariin exhibited downregulated levels of LC, Beclin-1 and ATG5 expression that were accompanied by upregulated p62 expression, indicating inactivation of the autophagic pathway. These results are consistent with the autophagy phenomenon that was observed by electron microscopy. Interestingly, increased levels of p-AKT and p-mTOR protein were evident in cells treated with cisplatin + icariin when compared with cisplatin alone. The phosphorylation of AKT and mTOR is considered as a biomarker for the activation of AKT/mTOR signaling, as well as for AKT and mTOR activity $(39,40)$. The AKT/mTOR pathway serves a critical role in cancer development and functions as a major regulator of autophagy progression $(12,41)$. Evidence has indicated that AKT can be inhibited by rapamycin, an inhibitor of mTOR (18); thus autophagy may be induced via inhibition of AKT/mTOR pathway. In the present study inhibition of the PI3K/AKT/mTOR pathway was proposed to activate autophagy, whereas induction of the pathway suppressed autophagy (42).

In the present study, activation of the AKT/mTOR pathway may have been responsible for the decreased autophagy in cells treated with cisplatin + icariin when compared with cisplatin alone. Therefore, icariin may inhibit autophagy via the AKT/mTOR pathway to re-sensitize SKVCR to cisplatin. A recent study demonstrated that Tanshinone IIA mediated autophagy via the PI3K/AKT/mTOR pathway in oral squamous cancer (43). Similarly, the PI3K/AKT/mTOR pathway has been proposed to be involved in the autophagic process mediated by a neuroactive compound (44). Furthermore, it has been demonstrated that the prototype mTOR inhibitor, rapamycin, can initiate cellular autophagy (45). The rapamycin-mediated attenuation of mTOR leads to overexpression of LC3B II and Beclin-1 in the infant brain (42). In the present study, rapamycin treatment notably reversed the effects of icariin on p-AKT, p-mTOR, and autophagy-associated protein expression. This further confirmed that icariin had activated the AKT/mTOR pathway, induced the downregulation of LC3B, Beclin-1 and ATG5, while upregulating p62. Therefore, icariin-mediated inhibition of autophagy may occur via activation of the AKT/mTOR pathway.

Additionally, overexpression of ATG5 was observed to impair the phosphorylation of AKT and mTOR, upregulate LC3B and Beclin-1, and downregulate p62. ATG5 is anchored to the phagophore membrane in a complex with ATG12 and ATG16 (46). Hu et al (47) reported that ATG5 upregulation affects pseudotube formation by enhancing the activation of AKT in endothelial progenitor cells. In bovine aortic endothelial cells, AKT activation and ROS production are stimulated by elevated ATG5 levels (48). In the present study, we also found that ATG5 overexpression decreased the activation of AKT. Furthermore, ATG5 accumulation may lead to a negative feedback to the upstream signal involving AKT and mTOR. Therefore, the phosphorylation of downstream mTOR was reduced, which led to activation of the autophagic pathway via inhibition of AKT/mTOR signaling in SKVCR cells with overexpression of ATG5.

Activation of the apoptosis process has been reported to be responsible for the cytotoxic effects of chemotherapy on tumor cells; however, alterations in the apoptotic components are usually associated with the sensitivity of tumor cells to chemotherapy (49). It has been revealed that apoptosis is negatively correlated with the AKT/mTOR pathway in numerous types of cancer (50). For example, cell proliferation was stimulated and apoptosis was suppressed by leptin via its ability to activate the PI3K/AKT/mTOR pathway (50). Thioridazine prevented the growth of cervical and endometrial cancer cells via its ability to induce apoptosis mediated by the $\mathrm{PI} 3 \mathrm{~K} / \mathrm{AKT} / \mathrm{mTOR} / \mathrm{p} 70 \mathrm{~S} 6 \mathrm{~K}$ pathway (51). We observed that, compared with cisplatin alone, treatment with cisplatin + icariin inhibited cell viability, and also activated apoptosis and the AKT/mTOR pathway. The present study proposed that the inhibition of viability and induction of apoptosis were not directly associated with the AKT/mTOR pathway. Crosstalk between autophagy and apoptosis has been demonstrated (10). Under certain circumstances, such as nutrient deficiency, abrogation of autophagy can accelerate cell death and activate certain apoptosis-associated enzymes, including caspases (52). Tumor cells can enhance their basal levels of autophagy for the purpose of maintaining their mitochondrial function and energy homeostasis to meet the elevated metabolic demands of growth and viability $(53,54)$. Conversely, autophagy-induced apoptosis was proposed as a method for treating cancer. Autophagic cell death is another type of cell death, which is morphologically different from apoptosis and was reported to be induced by high levels of autophagy (55). Caspase-3 is a key catalyst of apoptosis in mammalian cells (56). Our results suggested that tumor cells may induce autophagy for the purpose of surviving when treated with cisplatin, whereas icariin treatment decreased autophagy, thereby increasing the sensitivity of tumor cells to cisplatin rather than their propensity to autophagic cell death, which is characterized by the dysregulation of apoptosis-associated proteins. Icariin was proposed to enhance the susceptibility of SKVCR cells to the chemotherapeutic agent cisplatin by regulating autophagy induced by activation of the AKT/mTOR pathway.

In conclusion, our results are the first to demonstrate that icariin enhanced ovarian cell sensitivity to cisplatin by reducing autophagy in SKVCR cells by mediating the AKT/mTOR/ATG5 signaling pathway, to the best of our knowledge. Autophagy may serve a major role as a chemotherapy sensitization mechanism in SKVCR cells treated with icariin. Thus, effective suppression of autophagy may provide a prospective method for enhancing the cisplatin-induced inhibition of SKVCR cell growth and be used to improve the clinical outcomes of chemotherapy.

\section{Acknowledgements}

Not applicable. 


\section{Funding}

The present study was supported by the Shenzhen Basic Research Program (grant no. 20160427191320225).

\section{Availability of data and materials}

All data generated or analyzed during this study are included in this published article.

\section{Authors' contributions}

SJ made substantial contributions to the design of the present study. SJ and HC performed all the experiments and collected all the data; SJ, DF, HC and SD analyzed the data. SJ and DF drafted the manuscript, which was revised by HC. All authors approved the manuscript.

\section{Ethics approval and consent to participate}

Not applicable.

\section{Patient consent for publication}

Not applicable.

\section{Competing interests}

The authors declare they have no competing interests.

\section{References}

1. Jelovac D and Armstrong DK: Recent progress in the diagnosis and treatment of ovarian cancer. CA Cancer J Clin 61: 183-203, 2011.

2. Siegel R, Naishadham D and Jemal A: Cancer statistics, 2013 CA Cancer J Clin 63: 11-30, 2013.

3. Iorio MV, Visone R, Di Leva G, Donati V, Petrocca F, Casalini P, Taccioli C, Volinia S, Liu CG, Alder H, et al: MicroRNA signatures in human ovarian cancer. Cancer Res 67: 8699-8707, 2007.

4. Agarwal R and Kaye SB: Ovarian cancer: Strategies for overcoming resistance to chemotherapy. Nat Rev Cancer 3: 502-516, 2003.

5. Yang ZJ, Chee CE, Huang $\mathrm{S}$ and Sinicrope FA: The role of autophagy in cancer: Therapeutic implications. Mol Cancer Ther 10: 1533-1541, 2011

6. Mizushima N, Levine B, Cuervo AM and Klionsky DJ: Autophagy fights disease through cellular self-digestion. Nature 451: 1069-1075, 2008

7. Rubinsztein DC: The roles of intracellular protein-degradation pathways in neurodegeneration. Nature 443: 780-786, 2006.

8. Lum JJ, Bauer DE, Kong M, Harris MH, Li C, Lindsten T and Thompson CB: Growth factor regulation of autophagy and cell survival in the absence of apoptosis. Cell 120: 237-248, 2005 .

9. Onodera J and Ohsumi Y: Autophagy is required for maintenance of amino acid levels and protein synthesis under nitrogen starvation. J Biol Chem 280: 31582-31586, 2005.

10. Maiuri MC, Zalckvar E, Kimchi A and Kroemer G: Self-eating and self-killing: Crosstalk between autophagy and apoptosis. Nat Rev Mol Cell Biol 8: 741-752, 2007.

11. Kim KW, Myers CJ, Jung DK and Lu B: NVP-BEZ-235 enhances radiosensitization via blockade of the $\mathrm{PI} 3 \mathrm{~K} / \mathrm{mTOR}$ pathway in cisplatin-resistant non-small cell lung carcinoma. Genes Cancer 5: 293-302, 2014

12. Shinojima N, Yokoyama T, Kondo $\mathrm{Y}$ and Kondo S: Roles of the Akt/mTOR/p70S6K and ERK1/2 signaling pathways in curcumin-induced autophagy. Autophagy 3: 635-637, 2007.
13. Engelman JA, Luo J and Cantley LC: The evolution of phosphatidylinositol 3-kinases as regulators of growth and metabolism. Nat Rev Genet 7: 606-619, 2006.

14. Li X, Hu X, Wang J, Xu W, Yi C, Ma R and Jiang H: Inhibition of autophagy via activation of $\mathrm{PI} 3 \mathrm{~K} / \mathrm{Akt} / \mathrm{mTOR}$ pathway contributes to the protection of hesperidin against myocardial ischemia/reperfusion injury. Int J Mol Med 42: 1917-1924, 2018.

15. Wu YT, Tan HL, Shui G, Bauvy C, Huang Q, Wenk MR, Ong CN Codogno P and Shen HM: Dual role of 3-methyladenine in modulation of autophagy via different temporal patterns of inhibition on class I and III phosphoinositide 3-kinase. J Biol Chem 285: 10850-10861, 2010.

16. Marone R, Cmiljanovic V, Giese B and Wymann MP: Targeting phosphoinositide 3-kinase: Moving towards therapy. Biochim Biophys Acta 1784: 159-185, 2008.

17. Li J, Hou N, Faried A, Tsutsumi S, Takeuchi T and Kuwano H: Inhibition of autophagy by 3-MA enhances the effect of 5-FU-induced apoptosis in colon cancer cells. Ann Surg Oncol 16: 761-771, 2009.

18. Liu D, Yang Y, Liu Q and Wang J: Inhibition of autophagy by 3-MA potentiates cisplatin-induced apoptosis in esophageal squamous cell carcinoma cells. Med Oncol 28: 105-111, 2011.

19. Singh BN, Kumar D, Shankar S and Srivastava RK: Rottlerin induces autophagy which leads to apoptotic cell death through inhibition of $\mathrm{PI} 3 \mathrm{~K} / \mathrm{Akt} / \mathrm{mTOR}$ pathway in human pancreatic cancer stem cells. Biochem Pharmacol 84: 1154-1163, 2012.

20. Liu B, Xu C, Wu X, Liu F, Du Y, Sun J, Tao J and Dong J: Icariin exerts an antidepressant effect in an unpredictable chronic mild stress model of depression in rats and is associated with the regulation of hippocampal neuroinflammation. Neuroscience 294: 193-205, 2015

21. Tang Y, Jacobi A, Vater C, Zou L, Zou X and Stiehler M: Icariin promotes angiogenic differentiation and prevents oxidative stress-induced autophagy in endothelial progenitor cells. Stem Cells 33: 1863-1877, 2015.

22. Mo ZT, Li WN, Zhai YR and Gong QH: Icariin attenuates OGD/R-induced autophagy via Bcl-2-dependent cross talk between apoptosis and autophagy in PC12 cells. Evid Based Complement Alternat Med 2016: 4343084, 2016.

23. Fan C, Yang Y, Liu Y, Jiang S, Di S, Hu W, Ma Z, Li T, Zhu Y, $\mathrm{Xin} \mathrm{Z}$, et al: Icariin displays anticancer activity against human esophageal cancer cells via regulating endoplasmic reticulum stress-mediated apoptotic signaling. Sci Rep 6: 21145, 2016.

24. Wu X, Qiao B, Liu Q and Zhang W: Upregulation of extracellular matrix metalloproteinase inducer promotes hypoxia-induced epithelial-mesenchymal transition in esophageal cancer. Mol Med Rep 12: 7419-7424, 2015.

25. Harhaji-Trajkovic L, Vilimanovich U, Kravic-Stevovic T, Bumbasirevic V and Trajkovic V: AMPK-mediated autophagy inhibits apoptosis in cisplatin-treated tumour cells. J Cell Mol Med 13: 3644-3654, 2009.

26. Jiang S, Chang H, Deng S and Fan D: Icariin inhibits autophagy and promotes apoptosis in SKVCR cells through mTOR signal pathway. Cell Mol Biol 64: 4-10, 2018.

27. Wang SS, Chen YH, Chen N, Wang LJ, Chen DX, Weng HL, Dooley $\mathrm{S}$ and Ding HG: Hydrogen sulfide promotes autophagy of hepatocellular carcinoma cells through the PI3K/Akt/mTOR signaling pathway. Cell Death Dis 8: e2688, 2017.

28. Guo L, Zhao J, Qu Y, Yin R, Gao Q, Ding S, Zhang Y, Wei J and Xu G: microRNA-20a inhibits autophagic process by targeting ATG7 and ATG16L1 and favors mycobacterial survival in macrophage cells. Front Cell Infect Microbiol 6: 134, 2016.

29. Chen Y, Zhou X, Qiao J and Bao A: MiR-142-3p overexpression increases chemo-sensitivity of NSCLC by inhibiting HMGB1-mediated autophagy. Cell Physiol Biochem 41: 1370-1382, 2017.

30. Chang Z, Huo L, Li K, Wu Y and Hu Z: Blocked autophagy by miR-101 enhances osteosarcoma cell chemosensitivity in vitro. ScientificWorldJournal 2014: 794756, 2014.

31. Kim C,Kim W, Lee H, Ji E, Choe YJ, Martindale JL, Akamatsu W, Okano H, Kim HS, Nam SW, et al: The RNA-binding protein $\mathrm{HuD}$ regulates autophagosome formation in pancreatic $\beta$ cells by promoting autophagy-related gene 5 expression. J Biol Chem 289: 112-121, 2014.

32. Jiang K, Li Y, Zhu Q, Xu J, Wang Y, Deng W, Liu Q, Zhang G and Meng S: Pharmacological modulation of autophagy enhances Newcastle disease virus-mediated oncolysis in drug-resistant lung cancer cells. BMC Cancer 14: 551, 2014.

33. Eskelinen EL and Saftig P: Autophagy: A lysosomal degradation pathway with a central role in health and disease. Biochim Biophys Acta 1793: 664-673, 2009. 
34. He C and Klionsky DJ: Regulation mechanisms and signaling pathways of autophagy. Annu Rev Genet 43: 67-93, 2009.

35. Yousefi S, Perozzo R, Schmid I, Ziemiecki A, Schaffner T, Scapozza L, Brunner T and Simon HU: Calpain-mediated cleavage of Atg5 switches autophagy to apoptosis. Nat Cell Biol 8: 1124-1132, 2006.

36. McKnight NC and Zhenyu Y: Beclin 1, an essential component and master regulator of PI3K-III in health and disease. Curr Pathobiol Rep 1: 231-238, 2013.

37. Wilkinson DS, Jariwala JS, Anderson E, Mitra K, Meisenhelder J, Chang JT, Ideker T, Hunter T, Nizet V, Dillin A, et al: Phosphorylation of LC3 by the Hippo kinases STK3/STK4 is essential for autophagy. Mol Cell 57: 55-68, 2015.

38. Sheng R, Zhang LS, Han R, Liu XQ, Gao B and Qin ZH: Autophagy activation is associated with neuroprotection in a rat model of focal cerebral ischemic preconditioning. Autophagy 6: 482-494, 2010.

39. Akcakanat A, Sahin A, Shaye AN, Velasco MA and MericBernstam F: Comparison of Akt/mTOR signaling in primary breast tumors and matched distant metastases. Cancer 112: 2352-2358, 2008.

40. Chiang GG and Abraham RT: Phosphorylation of mammalian target of rapamycin (mTOR) at Ser-2448 is mediated by p70S6 kinase. J Biol Chem 280: 25485-25490, 2005.

41. Chang L, Graham PH, Hao J, Ni J, Bucci J, Cozzi PJ, Kearsley JH and $\mathrm{Li}$ Y: PI3K/Akt/mTOR pathway inhibitors enhance radiosensitivity in radioresistant prostate cancer cells through inducing apoptosis, reducing autophagy, suppressing NHEJ and HR repair pathways. Cell Death Dis 5: e1437, 2014.

42. Heras-Sandoval D, Pérez-Rojas JM, Hernández-Damián J and Pedraza-Chaverri J: The role of PI3K/AKT/mTOR pathway in the modulation of autophagy and the clearance of protein aggregates in neurodegeneration. Cell Signal 26: 2694-2701, 2014.

43. Qiu Y, Li C, Wang Q, Zeng X and Ji P: Tanshinone IIA induces cell death via Beclin-1-dependent autophagy in oral squamous cell carcinoma SCC-9 cell line. Cancer Med 7: 397-407, 2018.

44. Saiki S, Sasazawa Y, Imamichi Y, Kawajiri S, Fujimaki T, Tanida I, Kobayashi H, Sato F, Sato S, Ishikawa K, et al: Caffeine induces apoptosis by enhancement of autophagy via $\mathrm{PI} 3 \mathrm{~K} / \mathrm{Akt} / \mathrm{mTOR} / \mathrm{p} 70 \mathrm{~S} 6 \mathrm{~K}$ inhibition. Autophagy 7: 176-187, 2011.

45. Nazio F, Strappazzon F, Antonioli M, Bielli P, Cianfanelli V, Bordi M, Gretzmeier C, Dengjel J, Piacentini M, Fimia GM, et al: mTOR inhibits autophagy by controlling ULK1 ubiquitylation, self-association and function through AMBRA1 and TRAF6. Nat Cell Biol 15: 406-416, 2013.
46. Klionsky DJ, Cuervo AM and Seglen PO: Methods for monitoring autophagy from yeast to human. Autophagy 3: 181-206, 2007.

47. Hu N, Kong LS, Chen H, Li WD, Qian AM, Wang XY, Du XL, Li CL, Yu XB and Li XQ: Autophagy protein 5 enhances the function of rat EPCs and promotes EPCs homing and thrombus recanalization via activating AKT. Thromb Res 136: 642-651, 2015.

48. Du J, Teng RJ, Guan T, Eis A, Kaul S, Konduri GG and Shi Y: Role of autophagy in angiogenesis in aortic endothelial cells. Am J Physiol Cell Physiol 302: C383-C391, 2012.

49. Eramo A, Ricci-Vitiani L, Zeuner A, Pallini R, Lotti F, Sette G, Pilozzi E, Larocca LM, Peschle C and De Maria R: Chemotherapy resistance of glioblastoma stem cells. Cell Death Differ 13: 1238-1241, 2006.

50. Wang D, Chen J, Chen H, Duan Z, Xu Q, Wei M, Wang L and Zhong M: Leptin regulates proliferation and apoptosis of colorectal carcinoma through PI3K/Akt/mTOR signalling pathway. J Biosci 37: 91-101, 2012.

51. Kang S, Dong SM, Kim BR, Park MS, Trink B, Byun HJ and Rho SB: Thioridazine induces apoptosis by targeting the $\mathrm{PI} 3 \mathrm{~K} / \mathrm{Akt} / \mathrm{mTOR}$ pathway in cervical and endometrial cancer cells. Apoptosis 17: 989-997, 2012.

52. Jiang W and Ogretmen B: Autophagy paradox and ceramide. Biochim Biophys Acta 1841: 783-792, 2014.

53. Lin YC, Lin JF, Wen SI, Yang SC, Tsai TF, Chen HE, Chou KY and Hwang TI: Inhibition of high basal level of autophagy induces apoptosis in human bladder cancer cells. J Urol 195: 1126-1135, 2016

54. White E, Mehnert JM and Chan CS: Autophagy, metabolism, and cancer. Clin Cancer Res 21: 5037-5046, 2015.

55. Schweichel JU and Merker HJ: The morphology of various types of cell death in prenatal tissues. Teratology 7: 253-266, 1973.

56. He Z, Ma WY, Hashimoto T, Bode AM, Yang CS and Dong Z: Induction of apoptosis by caffeine is mediated by the p53, Bax, and caspase 3 pathways. Cancer Res 63: 4396-4401, 2003.

This work is licensed under a Creative Commons Attribution-NonCommercial-NoDerivatives 4.0 International (CC BY-NC-ND 4.0) License. 